\title{
Covid-19: Vacina boa é a aplicada de forma adequada
}

\section{Covid-19: Good vaccine is applied properly}

\author{
Márden Cardoso Miranda $\operatorname{Hott}^{1}[\mathbb{D}$
}

1. Docente do Programa de Pós-Graduação em Educadores da Saúde pela Universidade Federal de Minas Gerais (UFMG), Belo Horizonte, MG, Brasil.

\begin{abstract}
Resumo
Na atualidade, fotografar ou gravar o instante da imunização contra a Covid-19 se tornou rotina compartilhada nas redes sociais. Essa exposição instigou a observação de uma questão relevante: a técnica de aplicação está correta? Com a veiculação de imagens, é possível visualizar as vacinas sendo administradas em diferentes áreas do músculo deltoide, o que pode acarretar efeitos adversos. A otimização da qualificação técnica e pedagógica dos profissionais que elaboram e ministram as capacitações, bem como o envolvimento efetivo dos vacinadores nos treinamentos para injeção intramuscular é uma necessidade constante para evitar mais danos à saúde da população.
\end{abstract}

Palavras-chave: Covid-19; Imunização; Técnica vacinal; Capacitação; Efeitos adversos.

\begin{abstract}
Currently, photographing or recording the instant of immunization against Covid-19 has become a shared routine on social networks. This exposition prompted the observation of a relevant question: is the application technique correct? With the transmission of images, it is possible to visualize the vaccines being administered in different areas of the deltoid muscle, which can cause adverse effects. The optimization of the technical and pedagogical qualification of the professionals who design and deliver the training, as well as the effective involvement of vaccinators in training for intramuscular injection, is a constant need to avoid further damage to the health of the population.
\end{abstract}

Keywords: Covid-19; Immunization; Vaccine Technique; Training; Adverse Effects.

Em janeiro de 2021, chegou ao Brasil o primeiro lote de vacinas contra a Covid-19. Ainda que ocorram críticas quanto à demora da aquisição do imunizante, nesse período, os impasses sobre tomar ou não as doses recomendadas pela Organização Mundial da Saúde (OMS) e pelo Ministério da Saúde (MS) abriram um leque de questionamentos que variavam desde controvérsias sobre a eficácia do imunológico até possíveis efeitos colaterais diversos.

O fato é que, à medida em que foram aplicadas as primeiras doses vacinais, e a comunidade percebeu não haver significativas adversidades, as pessoas (ao que parece em maioria) se renderam a elas, consideradas como a forma mais segura na prevenção da Síndrome Respiratória Aguda Grave, associada às barreiras físicas (uso de máscaras, higienização das mãos, distanciamento social) tão necessárias quanto à imunização coletiva.

Dessa forma, a partir do momento em que a vacina começou a ser administrada nos grupos prioritários (idosos) e foi ampliando a abrangência para grupos diversos (profissionais da saúde, portadoras de comorbidades, puérperas, gestantes, entre outros), uma avalanche de postagens de fotos e vídeos registrando o instante da aplicação inundou as redes sociais. $\mathrm{Na}$ "mídia", fotografar ou gravar a imunização se tornou uma rotina compartilhada, transformando o ato em incentivo, alívio e, por vezes, em ostentação - considerando o privilégio de estar entre os primeiros em função da inicial escassez de doses, mas que vem alcançando maior cobertura gradativamente, conforme novas aquisições do MS.

No entanto, essa exposição pública levou à descoberta de uma série de episódios inusitados, mas, para além, instigou a observação de uma questão que pode parecer simples ao leigo, porém de extrema relevância metodológica: a técnica de aplicação, propriamente dita, está correta?

A frase popularizada: "Vacina boa é a vacina no braço" - pois com a diversificação dos tipos de imunizantes, alguns populares procuram escolher, equivocadamente, aquele que considera melhor - deveria ser alterada para: "Vacina boa é a aplicada de forma adequada". Isto porque "os principais erros que acontecem na sala de vacina estão relacionados à técnica de aplicação" ${ }^{1}$ e "a Organização Pan-Americana da Saúde (OPAS) incentiva as pessoas a tomarem qualquer vacina contra a COVID-19 que thes seja oferecida pela autoridade nacional de saúde"2.

Na prática, ocorreram - desde o início da vacinação contra a Covid-19 até o momento - inúmeras ofertas gratuitas de capacitação para o contingente da saúde, tanto na modalidade a distância, como presencial - especialmente destinadas àqueles 
que compõem a Atenção Primária à Saúde-, em parceria com diversos órgãos, a exemplo da Coordenação Geral do Programa Nacional de Imunizações ${ }^{3}$ :

A CGPNI, visando aumentar a capilaridade da informação, em conjunto do Conselho Nacional de Secretarias Municipais de Saúde (Conasems), Conselho Nacional de Secretários de Saúde (Conass), Fundação Oswaldo Cruz (Fiocruz) e Apoiadores do MS/OPAS atuante nos Estados está disponibilizando capacitações voltadas para a qualificação de profissionais da saúde do SUS que atuarão nas campanhas de vacinação contra a Covid-19, em especial aos profissionais inseridos na Atenção Primária em Saúde e nas cerca de $\mathbf{3 8}$ mil salas de vacinas existentes no país.

(Ministério da Saúde, 2021)

Entre a gama de quesitos necessários para garantir a eficácia de uma vacina, que englobam desde o controle de qualidade na fabricação, o transporte, o armazenamento, o preparo e a aplicação - esta última, com a socialização de imagens, tornou possível visualizar a administração em diferentes áreas do braço, região eleita como a mais adequada para tal, conforme a Fundação Nacional de Saúde (FUNASA) do $\mathrm{MS}^{4}$, em texto e na Imagem 1 - a seguir:

Nesta região existe o músculo deltoide, o mais importante da cintura escapular. É uma região de grande sensibilidade local e possui pequena massa muscular. Serve para aplicação de pequena quantidade de solução $(1$ a $3 \mathrm{ml}$ ) [...]. Para a localização da punção deve-se traçar um retângulo na região lateral do braço, iniciando na extremidade mais inferior do acrômio, respeitando a distância de $3-5 \mathrm{~cm}$ abaixo do acrômio, e terminando no ponto oposto à axila, a $3-3,5 \mathrm{~cm}$ acima da margem inferior do deltoide. Localizar a punção neste retângulo.

(Ministério da Saúde, 2001)

Figura 1. Localização correta para injeção na musculatura deltoide.

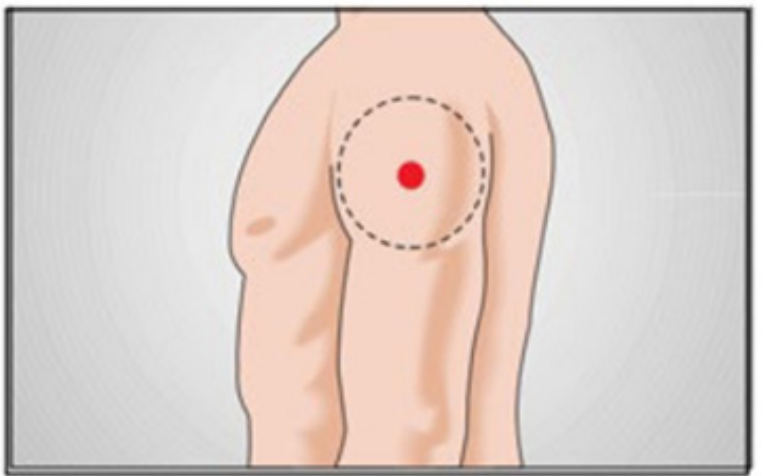

Fonte: FUNASA - Ministério da Saúde (2001).

O documento mais recente, específico para a administração de imunobiológicos - constante no anexo do MS, intitulado "Orientações quanto à aplicação de vacina intramuscular e a não indicação de aspiração" ${ }^{5}$ - complementa e atualiza em negrito:

$\mathrm{Na}$ utilização da via intramuscular, o imunobiológico é introduzido no tecido muscular, cuja vascularização [...] proporciona a absorção [...] de forma mais rápida. [...] As regiões anatômicas selecionadas para a injeção intramuscular devem estar distantes dos grandes nervos e de vasos sanguíneos [...]. Dentro dos procedimentos para vacinação, destacamos que, a aspiração no momento da administração do imunobiológico em tecido muscular, para verificar se foi atingido vaso sanguíneo, não está mais indicada.

(Ministério da Saúde, 2020)

O referido documento ${ }^{5}$ ainda norteia e reforça o procedimento:

“[...] avalie a região anatômica indicada para a administração de cada imunobiológico, considerando a integridade e a massa muscular à palpação, evitando locais com endurecimento ou doloridos, com cicatrizes, manchas, tatuagens e lesões; localize o músculo deltoide identificando o acrômio, marque $3 \mathrm{~cm}$ [...] abaixo do acrômio e trace um triângulo imaginário com a base voltada para cima; introduza a agulha no centro

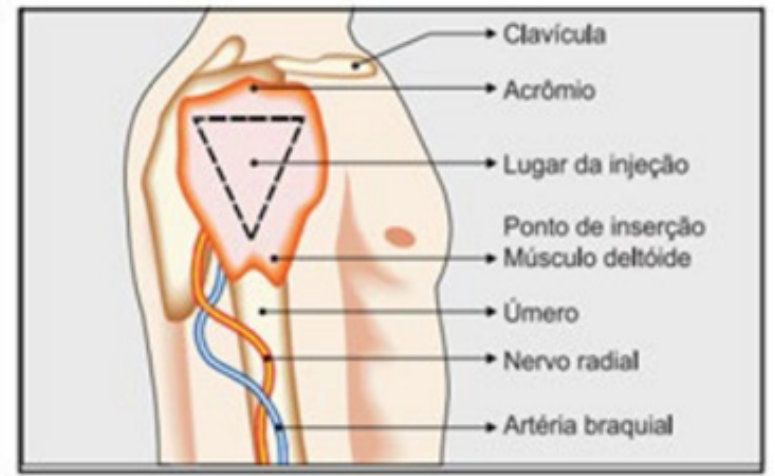

do triângulo imaginário em ângulo reto (90o); injete o imunobiológico rapidamente; retire a agulha em movimento único e firme; faça leve compressão no local com algodão seco. Não friccione o local onde a vacina foi aplicada [...]."

(Ministério da Saúde, 2020)

A musculatura deltoide cobre a parte superior do braço; no entanto, possui espessura diferente em toda a sua extensão. O que se tem visto, em alguns casos, é a aplicação de vacinas no terço superior desse músculo. Neste sentido, em publicação específica para a administração do imunizante contra o coronavírus, o Conselho Federal de Farmácia ${ }^{6}$ alerta:

É errado realizar a aplicação próximo ao ombro [...], pois poderá causar inflamação e lesões nas articulações. As recomendações mais recentes orientam que seja utilizada uma técnica chamada técnica em Z [...], mais apropriada para administração por via intramuscular. A prega, na via intramuscular, só em caso de pacientes muito magros ou idosos que têm pouco tecido muscular.

(Conselho Federal de Farmácia, 2021)

A técnica em $Z$ é defendida por vários profissionais da saúde para aplicação de imunizantes na região deltoide, embora seja historicamente indicada para injeção na região glútea. Basicamente, a técnica consiste em tracionar a pele da parte 
mais saliente do deltoide para baixo ou para o lado - antes da administração da vacina que, uma vez injetada e retirada a agulha, forma um ziguezague ( $Z$ ) pelo suave deslocamento do tecido que, ao ser solto, deixa o local onde o imunizante foi administrado desalinhado em relação ao trajeto da agulha, vedando o retorno do conteúdo.

Assim, garante que toda a dose fique depositada no músculo, sem extravasamento que ocasionaria perda do volume aplicado; auxilia na diminuição de efeitos colaterais locais como: desconforto, vermelhidão e nódulo na região da aplicação; evita a restrição de movimentos; promove a absorção adequada do imunizante, e contribui para melhor tolerância do organismo em geral. Sobre isso, a $\mathrm{OMS}^{7}$ enfatiza:

Os efeitos colaterais relatados das vacinas COVID-19 têm sido, em sua maioria, leves a moderados e não duraram mais do que alguns dias. Efeitos colaterais típicos incluem dor no local da injeção, febre, fadiga, dor de cabeça, dor muscular, calafrios e diarreia. As chances de qualquer um desses efeitos colaterais que ocorrem após a vacinação diferem de acordo com a vacina específica.

(Organização Mundial da Saúde, 2021)

Contudo, queixas sobre reações adversas surgem e, na maioria das vezes, são atribuídas à reação do sistema imunológico que busca produzir anticorpos, respondendo aos componentes da vacina. Mas, caso a técnica de aplicação esteja inadequada, o imunizante pode se alojar em outras regiões e provocar danos que, na verdade, não deveriam ser atribuídos, exclusivamente, à ação física da vacina, mas à aplicação incorreta. O MS afirma:

Os erros de imunização, consequentes de atitudes ou procedimentos não cumpridos conforme estabelecidos nas normas, por si só ou em conjunto, podem causar redução ou falta do efeito esperado e eventos adversos graves e até fatais. As práticas inadequadas de imunização podem resultar em danos [...] para as pessoas que a recebe. Os erros de imunização são preveníveis por meio de treinamento de pessoal [...] e de supervisão dos serviços.

(Ministério da Saúde, 2014)

Diante das incertezas para controle e erradicação da Covid-19, são diversas questões que emergem prestes ao estudo e aprimoramento. Referente à técnica de administração de vacinas, considerando, também, as ações precedentes e procedentes ao ato da injeção em si, faz-se necessário otimizar a qualificação técnica e pedagógica dos envolvidos na elaboração de capacitações e treinamentos.

A partir daí, torna-se imprescindível fomentar a oferta mais efetiva e monitorada de cursos que carecem prever - além do conhecimento técnico - a sensibilização dos vacinadores para que eles se envolvam com o aperfeiçoamento e busquem praticá-lo. Conhecer nem sempre está relacionado ao fazer que, ademais, concerne à conscientização sobre boas práticas em saúde.

Erros na administração vacinal estão ocorrendo e gerando problemas de saúde. Embora visíveis por meio do compartilhamento de informações, admite-se o relegar por se tratar de minoria. É possível que sejam considerados insignificantes - se comparados ao problema global pandêmico-, mas é legítimo o afetado apresentar complicações evitáveis, caso o tão defendido olhar holístico se isente de um exercício mais atento.

\section{REFERÊNCIAS}

1. Oliveira GCA, Imperador C, Ferreira ARO, Oliveira WR, Camparoto CW, Jesus WA, Machado RS, Machado MF. Assistência de enfermagem no processo de imunização: revisão da literatura. BJD [Internet]. 2021 Jan [acesso 2021 Ago 09]; 17(1): 7381-7395. Disponível em: https://www.brazilianjournals.com/index. php/BRJD/article/view/23447. DOI: https://doi.org/10.34117/bjdv7n1-499.

2. Organização Pan-Americana da Saúde. Perguntas frequentes: vacinas contra a COVID-19 [Internet]. Brasília: OPAS; Jul 2021 [acesso 2021 Ago 10]. Disponível em: https://www.paho.org/pt/vacinas-contra-covid-19/perguntas-frequentesvacinas-contra-covid-19.

3. Ministério da Saúde (BR). Plano Nacional de Operacionalização da Vacinação contra a Covid-19 [Internet]. Brasília: Coordenação Geral do Programa Nacional de Imunizações; Jan 2021 [acesso 2021 Ago 09]. Disponível em: https://www. gov.br/saude/pt-br/media/pdf/2021/marco/23/plano-nacional-de-vacinacaocovid-19-de-2021.

4. Ministério da Saúde (BR). Administração dos Imunobiológicos: Técnicas de Preparo, Vias e Locais de Administração [Internet]. Brasília: FUNASA; 2001 [acesso 2021 Ago 09]. Disponível em: https://bvsms.saude.gov.br/bvs/ publicacoes/funasa/salavac_treinando_textos11_20.pdf.
5 Ministério da Saúde (BR). Orientações quanto à aplicação de vacina intramuscular e a não indicação de aspiração [Internet]. Brasília: Secretaria de Vigilância em Saúde; 2020 [acesso 2021 Ago 09]. Disponível em: https://sei.saude.gov.br/sei/controlador_externo.php?acao=documento_ conferir\&codigo_verificador=0014128030\&codigo_crc=D371C3A9\&hash_

6- Conselho Federal de Farmácia. Aplicação de vacinas exige conhecimento para evitar erros [Internet]. Brasília: CFF; Maio 2021. [acesso 2021 Ago 09]. Disponível em: http://covid19.cff.org.br/aplicacao-de-vacinas-exige-conhecimento-paraevitar-erros/.

7. Organização Mundial da Saúde. Efeitos colaterais das vacinas COVID-19 [Internet]. Brasília: OPAS; Mar 2021. [acesso 2021 Ago 09]. Disponível em: https://www.who.int/pt/news-room/feature-stories/detail/side-effects-ofcovid-19-vaccines.

8. Mistério da Saúde (BR). Manual de Vigilância Epidemiológica de Eventos Adversos Pós-Vacinação [Internet]. 3. ed. Brasília: Ministério da Saúde; 2014 [acesso 2021 Ago 09]. Disponível em: https://bvsms.saude.gov.br/bvs/ publicacoes/manual_vigilancia_epidemiologica_eventos_adversos_pos_ vacinacao.pdf. 